\title{
Estrutura remuneratória dos servidores ativos civis do Executivo federal
}

\section{Enzo Bastos Profili 1}

${ }^{1}$ Northwestern University, Evanston / IL - Estados Unidos

\begin{abstract}
A administração pública federal passa por um momento de aperto fiscal, e, como o gasto com pessoal é um dos maiores componentes da despesa, mostra-se importante avaliar sua composição. Para isso, este artigo analisa detalhadamente a estrutura remuneratória das carreiras do Executivo federal civil. $\mathrm{O}$ texto mostra que a maioria dos servidores federais civis está entre os $10 \%$ mais bem remunerados do país, recebendo, em certos casos, um prêmio salarial com relação à esfera privada. Analisamos também que servidores com as mesmas atribuições têm remuneração significativamente diferente, dependendo do órgão da administração direta ou da entidade da administração indireta em que trabalham. Além disso, evidenciamos a prociclicalidade da despesa com pessoal ativo do Executivo, possivelmente liderada em tempos de recessão. Dito isso, uma agenda de reforma administrativa é importante para racionalizar as carreiras do serviço público, trazendo a remuneração à realidade brasileira e premiando servidores de alto desempenho por meio de metas de médio e longo prazos.
\end{abstract}

Palavras-chave: remuneração; servidor público federal; prêmio salarial.

\section{Estructura de remuneración de los funcionarios civiles del Ejecutivo federal en Brasil}

La Administración Pública Federal está atravesando un momento de ajuste fiscal y, como los gastos de personal son uno de los componentes más importantes del gasto público, es importante evaluar su composición. Para ello, este artículo analiza en detalle la estructura de remuneración de las carreras del Ejecutivo federal. El artículo muestra que la mayoría de los funcionarios federales se encuentra dentro del 10\% mejor remunerado del país, percibiendo en ciertos casos una prima salarial, como en la esfera privada y otros países. También inferimos que los funcionarios públicos con las mismas atribuciones tienen una remuneración significativamente diferente, dependiendo del cuerpo de la administración directa o indirecta en la que trabajan. Además, evidenciamos la prociclicidad del gasto en personal activo del Ejecutivo federal. Dicho esto, es importante una agenda de reforma administrativa para racionalizar las carreras del servicio público, traer la remuneración a la realidad brasileña y recompensar a los funcionarios de alto rendimiento a través de metas a mediano y largo plazo.

Palabras clave: remuneración; servidor público federal; premio salarial.

\section{Compensation structure of the Federal Executive's active civil servants in Brazil}

The Brazilian Federal Public Administration is going through a period of fiscal tightening, and as personnel expenses are one of the largest components of expenditure, it is important to assess its composition. This article analyzes in detail the remuneration structure of executive branch careers. The article shows that most federal employees are among the $10 \%$ best-paid employees in the country, earning a salary premium relative to the private sector and other countries' public servants. Moreover, we show that civil servants with equivalent duties have significantly different remuneration, depending on the body of the direct or indirect administration in which they work. In addition, we highlight the procyclicality of the expenditure on executive branch active personnel. An administrative reform agenda is important to rationalize public service careers, provide remuneration in line with the Brazilian reality, and reward high-performance employees through medium and long-term goals.

Keywords: compensation; public servant; wage premium. 


\section{AGRADECIMENTOS}

Agradeço a Ricardo Dahis, Eduardo Haddad e Alexandre Porsse pela ajuda e pelos comentários. Também agradeço à Secretaria Especial de Desburocratização, Gestão e Governo Digital do Ministério da Economia pela ajuda na coleta dos dados, em especial a Vinicius Pecora. Também agradeço à Northwestern University pelo apoio financeiro que permitiu a realização deste texto. Finalmente, agradeço aos revisores anônimos e à editora pelos comentários que melhoraram a qualidade do texto.

\section{INTRODUÇÃO}

Atualmente, o Brasil passa por um momento de reformas, que têm como um dos objetivos dar fôlego às contas públicas. Uma dessas reformas é a administrativa, que visa alterar a estrutura remuneratória dos servidores e a estrutura de órgãos e entidades do Executivo federal. Neste artigo, focamos na estrutura remuneratória dos servidores federais civis do Executivo.

Forni e Novta (2014) mostram que, em tempos de consolidação fiscal, reformas administrativas têm mais efeito quando induzem mudanças estruturais e quando são fruto de diálogo com a sociedade. Por outro lado, congelamento de contratações e salários se mostram menos efetivos em longo prazo, pois são medidas paliativas.

Nesse cenário, o objetivo deste estudo é apontar ineficiências e distorções estruturais na remuneração dos servidores no Executivo federal civil para servir de apoio ao debate sobre a reforma administrativa. É importante frisar que este estudo é focado no Executivo civil do governo federal, que corresponde a aproximadamente $5 \%$ do total de servidores públicos no Brasil. Na segunda parte do texto, fazemos, em primeiro lugar, uma pesquisa documental do cenário atual com dados agregados e, depois, com dados específicos por carreira. Na terceira parte, procedemos a uma análise mais detalhada sobre a remuneração dos servidores, comparando-a com a da iniciativa privada, entre si e entre diferentes órgãos/entidades do Executivo federal. Na quarta parte, também analisamos a prociclicalidade da despesa com pessoal.

Para informações sobre os servidores civis do Executivo federal, este estudo utiliza dados de 3 fontes:

1) Portal de Transparência, para micro dados de servidores do mês de maio de 2019. Essa base conta com 550 mil servidores civis do Executivo federal, com nome, situação do vínculo, cargo, órgão/ entidade, ministério, data de ingresso no serviço público, remuneração básica e indenizações recebidas. Infelizmente, certos servidores não têm informações completas, de modo que a base foi reduzida para 445 mil.

2) Dados fornecidos pela Secretaria de Gestão e Desempenho de Pessoal (SGP/ME), para dados agregados de carreiras. Exploramos tais dados principalmente na segunda parte, que analisa as tabelas remuneratórias do serviço público federal. Essa base conta com dados de carreiras que abrangem 530 mil servidores - 480 mil efetivos e 50 mil cedidos -, com nível de escolaridade da carreira, número de servidores, número de servidores no topo, remuneração bruta, custo total da carreira anualizado (e por servidor) e idade média de aposentadoria. Com esses dados, adicionamos o nível de escolaridade do cargo à base do Portal da Transparência. É importante mencionar que as análises são do autor, e não da secretaria.

3) Painel Estatístico de Pessoal e Boletim Estatístico de Pessoal, do extinto Ministério do Planejamento - agora a cargo da SGP/ME -, que dispõem informações agregadas da administração pública federal, com dados de todos os 1,2 milhão de servidores ativos e inativos do Executivo federal. 


\section{SITUAÇÃO ATUAL}

\subsection{Número de Servidores}

Nesta seção, analisamos dados agregados e de carreiras para o ano de 2019. Atualmente, o governo federal conta com 622 mil servidores ativos civis, divididos em mais de 300 carreiras e 2,2 mil cargos, de acordo com o Painel Estatístico de Pessoal (PEP). O Gráfico 1 mostra o histórico do número de servidores no período entre 1991 e 2015, no qual há uma consistente divulgação de dados pelo Boletim Estatístico de Pessoal (BEP). Percebemos uma queda no número de servidores na década de 1990, iniciada no governo de Fernando Collor de Mello, por meio de seu programa de privatizações.

Na década de 2000, houve uma reposição desses servidores, e em 2015 o número já era maior do que o patamar de 1991. Cardoso e Nogueira (2017) argumentam que tal aumento na quantidade de servidores foi fruto da substituição de terceirizados, muitas vezes contratados irregularmente, por servidores efetivos. Ademais, Cavalcante e Carvalho (2017) argumentam que esse crescimento veio após um período de queda no número de servidores - eram mais de 700 mil em 1989 -, e hoje a esfera pública participa de mais funções. De fato, segundo a Organização para a Cooperação e o Desenvolvimento Econômico (OCDE), em 2014, os cargos públicos representavam 11,9\% do total de empregos no Brasil, enquanto a proporção média entre os países da OCDE era 18\%, segundo a própria (2017).

Desses 622 mil servidores, 240 mil trabalhavam na administração direta, enquanto 292 mil trabalhavam em autarquias federais, como o Instituto Nacional do Seguro Social (INSS) e a Comissão de Valores Mobiliários (CVM). Outros 90 mil, ainda, atuavam em fundações federais como o Instituto Brasileiro de Geografia e Estatística (IBGE) e o Instituto de Pesquisa Econômica Aplicada (Ipea).

\section{GRÁFICO 1 HISTÓRICO DA QUANTIDADE DE SERVIDORES ATIVOS CIVIS DO EXECUTIVO FEDERAL} (1991-2015)

\section{0}

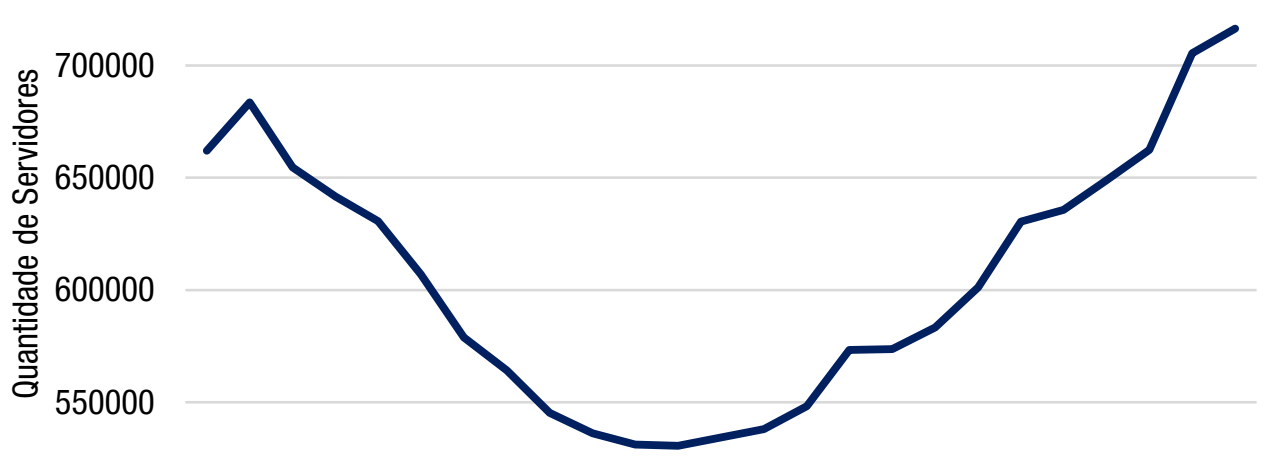

500000

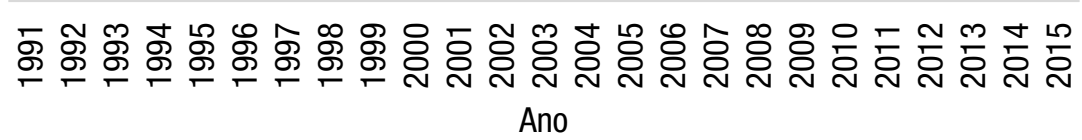

Fonte: Boletim Estatístico de Pessoal (2017). 
Segundo dados do PEP de junho de 2019, se incluirmos empresas públicas dependentes, o número de servidores sobe para 705 mil, divididos como na Tabela 1.

\section{TABELA 1 DIVISÃO DOS SERVIDORES POR REGIME DE TRABALHO}

\begin{tabular}{lr}
\hline Tipo de servidor & Quantidade \\
\hline Servidores efetivos ativos & 482.358 \\
\hline Empregados de empresas estatais dependentes & 78.964 \\
Temporários & 76.863 \\
Cedidos & 52.178 \\
Celetistas & 9.355 \\
Sem vínculo (comissionados) & 5.061 \\
\hline
\end{tabular}

Fonte: Painel Estatístico de Pessoal.

Quanto ao nível de escolaridade, Cavalcante e Carvalho (2017) mostram que, entre 1995 e 2014, houve uma mudança no perfil do servidor, com diminuição na proporção de profissionais de nível médio e aumento na de funcionários com nível superior, a fim de profissionalizar o serviço público e a burocracia brasileira. Segundo Palotti e Freire (2015), cargos de nível auxiliar foram progressivamente sendo substituídos por terceirizados.

Como mostrado na Tabela 2, o PEP indica que 59\% dos cargos dos servidores ativos permanentes (477 mil no total) são de nível superior, 38\% são de nível intermediário (ensino médio completo) e 3\% são de nível auxiliar (ensino fundamental). No entanto, $81 \%$ dos servidores têm nível superior e só $16 \%$ são de nível intermediário, de modo que milhares de servidores de nível superior estão em cargos de nível intermediário. Portanto, em muitos casos, existe uma qualificação em excesso dos servidores para os cargos, e alguns artigos abordam esse fenômeno no serviço público.

Francisco (2015) averiguou potenciais conflitos gerados pela sobrequalificação de técnicos de enfermagem do Sistema Único de Saúde (SUS), e entrevistados relataram que o nível superior não trouxe o reconhecimento esperado, o que, por sua vez, reduziu a produtividade no trabalho. Gonçalves (2017) também investigou o tema e argumenta que a sobrequalificação não é necessariamente um mal, mas requer gerenciamento ativo.

\section{TABELA 2 DIVISÃO DE CARGOS E SERVIDORES POR NIVEL DE ESCOLARIDADE}

\begin{tabular}{ccc} 
Nível & Escolaridade do cargo (\%) & Escolaridade do servidor (\%) \\
\hline Auxiliar & 2,94 & 3,53 \\
\hline Intermediário & 37,51 & 15,66 \\
Superior & 59,55 & 80,80 \\
\hline
\end{tabular}

Fonte: Painel Estatístico de Pessoal. 


\subsection{Remuneração de Servidores}

No Gráfico 2, pode-se ver a distribuição salarial dos servidores. Para os de nível auxiliar e intermediário, a remuneração se concentra entre $\mathrm{R} \$ 4,5$ mil e $\mathrm{R} \$ 7,5$ mil, acima da média do trabalhador brasileiro, que é próxima a R 1,5 mil, segundo a Pesquisa Nacional por Amostra de Domicílios (Pnad) Contínua de 2017. É importante frisar que há uma variação nas ocupações, tema aprofundado na seção 3.1 .

Para servidores de nível superior, há uma concentração alta a partir de R \$7,5 mil e 88 mil funcionários (16,7\% do total) com remuneração acima de R\$ 18 mil. Nessa amostra, havia 530 mil trabalhadores, que são os cerca de 480 mil efetivos ativos na administração pública federal (ADPF) mais os cerca de 50 mil cedidos pela ADPF.

\section{GRÁFICO 2 DISTRIBUIÇÃO DE RENDA DOS SERVIDORES POR ESCOLARIDADE}

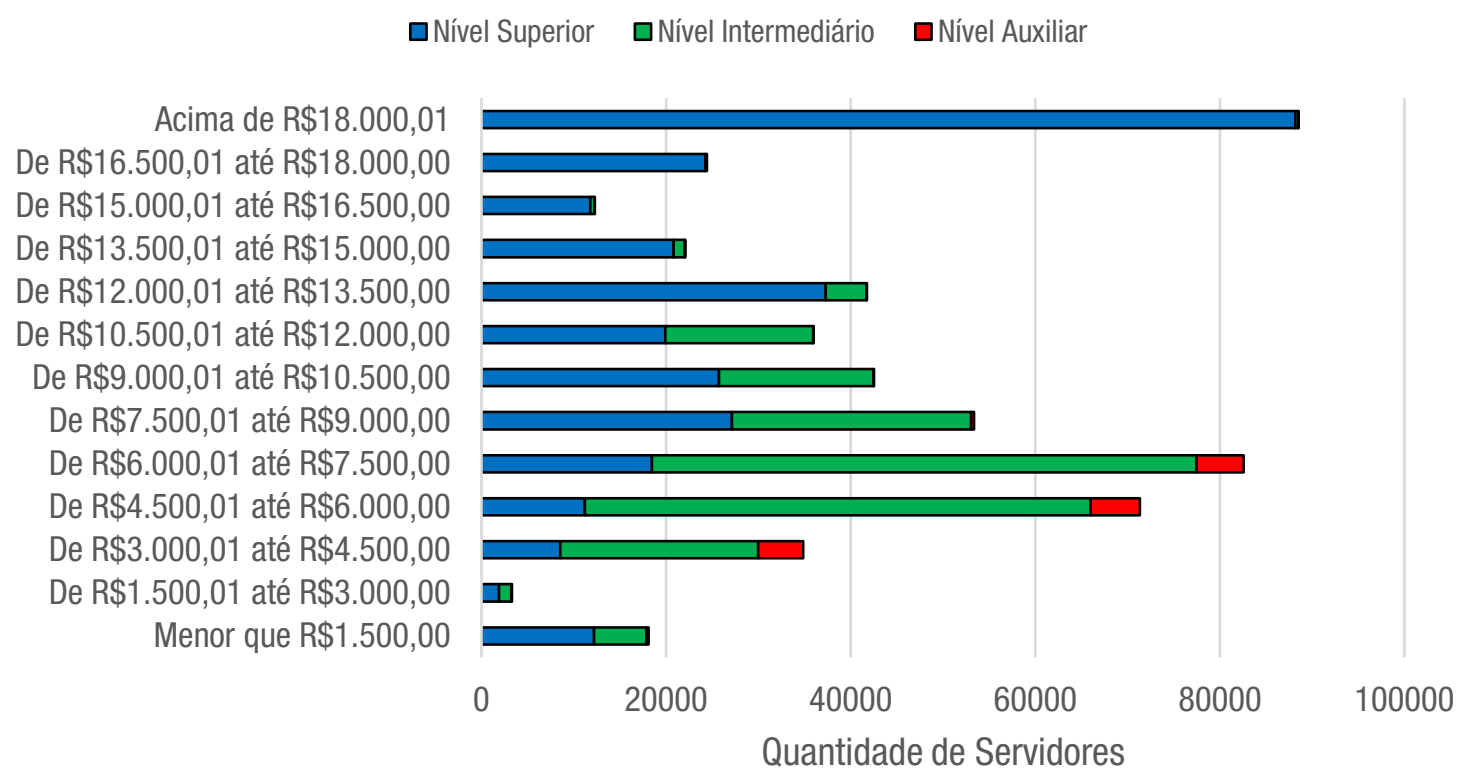

Fonte: Elaborado pelo autor com dados da SGP/ME.

Com base em dados de remuneração líquida - salário-base bruto deduzido de imposto de renda e contribuições previdenciárias, somado às verbas indenizatórias - dos servidores federais do Portal da Transparência (2019) e do rendimento médio mensal da população ocupada por classes de percentual em 2019 - rendimento médio mensal real das pessoas de 14 anos ou mais, em todos os trabalhos -, divulgados pelo IBGE (2019) e convertidos para reais, em maio de 2019, pelo Índice Nacional de Preços ao Consumidor Amplo (IPCA), podemos classificar a remuneração dos servidores em relação à da população ocupada. Como o dado do IBGE somente mostra a média de remuneração de uma faixa de renda, o cálculo coloca cada servidor na faixa de renda com a média mais próxima de sua remuneração. 
O Gráfico 3 apresenta a distribuição de servidores nas faixas de renda, e podemos averiguar que eles fazem parte do quintil mais alto de remuneração, com certa variação ao considerar níveis. Servidores de nível auxiliar e intermediário estão concentrados entre o quintil e o decil de maior renda, enquanto os de nível superior estão concentrados ao redor do top 5\%. Portanto, parte das distorções e das desigualdades podem ser endereçadas por uma estrutura tributária mais progressiva, atualmente em discussão no Congresso.

\section{GRÁFICO 3 APROXIMAÇÃO DA DISTRIBUIÇÃO DA RENDA DOS SERVIDORES NA RENDA NACIONAL}

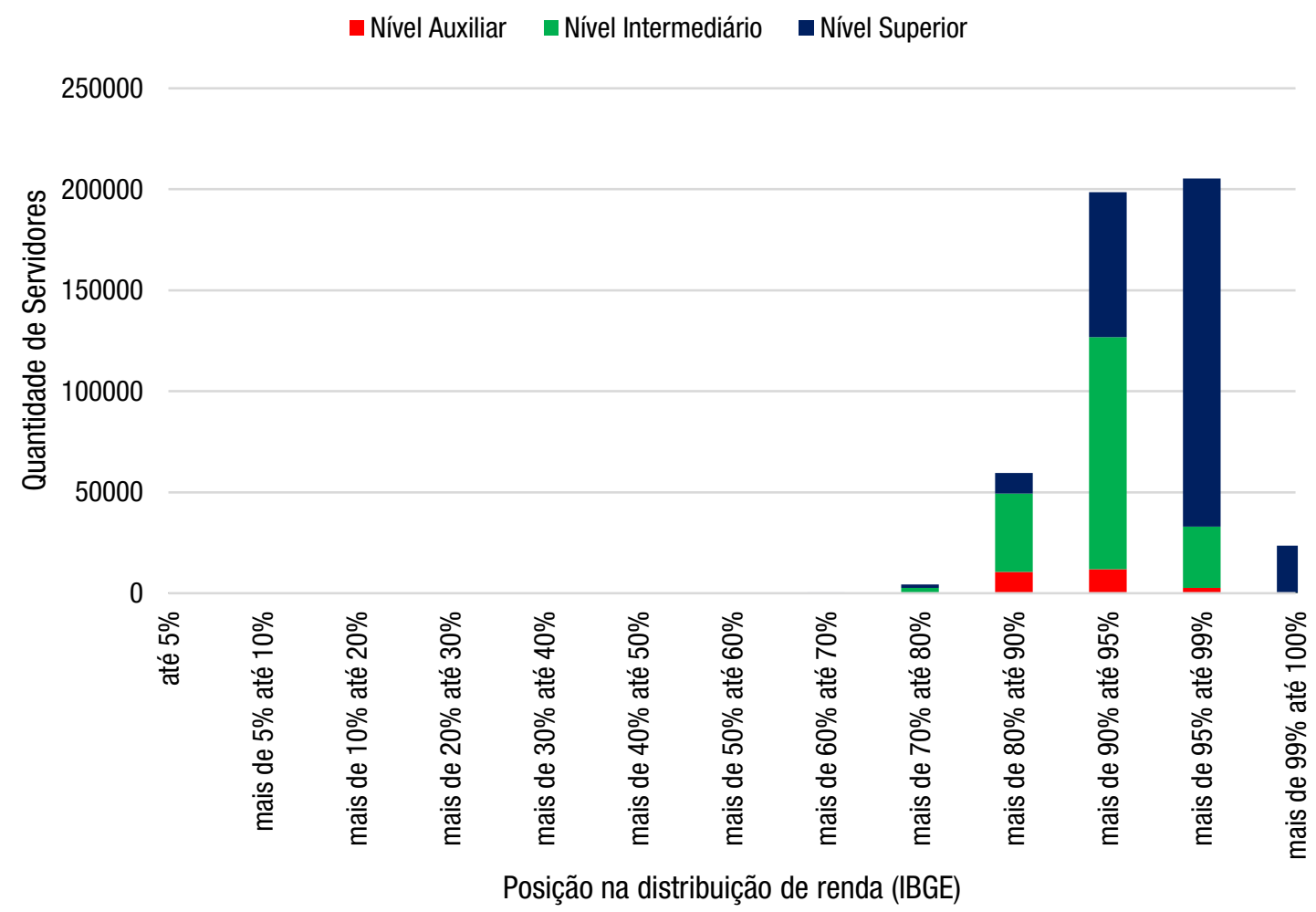

* Remuneração dos servidores inclui verbas indenizatórias.

** Servidores assinalados à faixa com remuneração média mais próxima de sua remuneração bruta.

Fonte: Elaborado pelo autor com dados do Portal da Transparência e do IBGE (2019).

\subsection{Maiores Tabelas Remuneratórias}

Usando dados da SGP/ME, a Tabela 3 mostra as 20 tabelas remuneratórias com mais servidores. A maior é a de técnicos em educação de nível médio, com 86 mil servidores, seguida de professores do magistério superior (78 mil) e do ensino básico (44 mil). 


\section{TABELA 3 VINTE MAIORES TABELAS REMUNERATÓRIAS}

\begin{tabular}{|c|c|}
\hline Tabela r & Quantidade (mil) \\
\hline Técnico em educação (nível médio) & 86 \\
\hline Prof. mag. superior (ded. excl.) & 78 \\
\hline Prof. ensino básico/Téc. (ded. excl.) & 44 \\
\hline Nível superior (NS), previdência, saúde e trabalho & 41 \\
\hline Técnico em educação (nível superior) & 40 \\
\hline $\begin{array}{l}\text { Plano geral de cargo do Poder Executivo (PGPE) - cargos de } \\
\text { nível intermediário }\end{array}$ & 20 \\
\hline Técnico do Seguro Social - nível intermediário (NI) - 40h & 18 \\
\hline Prof. mag. superior $-40 \mathrm{~h}$ & 10 \\
\hline Policial rodoviário federal & 10 \\
\hline Auditor fiscal da Receita Federal do Brasil (RFB) & 9 \\
\hline Prof. magistério superior - 20h & 7 \\
\hline Analista Tributário da RFB & 6 \\
\hline Agente da Polícia Federal & 6 \\
\hline Nível intermediário do Ministério da Fazenda & 6 \\
\hline Nível superior do PGPE & 6 \\
\hline NS Previdência, Saúde e Trabalho & 5 \\
\hline Nível auxiliar de combate de endemias & 5 \\
\hline Analista do Seguro Social & 4 \\
\hline Médico da carreira da Previdência - 20h & 4 \\
\hline Prof. ensino básico/Téc. - 40h & 4 \\
\hline
\end{tabular}

Fonte: SGP/ME

\subsection{Tabelas remuneratórias mais bem remuneradas}

Com relação às 20 tabelas remuneratórias de maior remuneração, podemos ver na Tabela 4 que as maiores estão no Banco Central, próximas a $\mathrm{R} \$ 500$ mil anuais. Acima de $\mathrm{R} \$ 400$ mil anuais também temos outras, como as de procuradores da fazenda e auditores fiscais. 


\section{TABELA 4 VINTE TABELAS REMUNERATÓRIAS DE MAIOR REMUNERAÇÃO}

\begin{tabular}{|c|c|}
\hline Tabela remuneratória & Remuneração anual (R\$) \\
\hline Procurador do Banco Central & 499.005 \\
\hline Analista do Banco Central & 484.157 \\
\hline Procurador da Fazenda Nacional & 465.399 \\
\hline Auditor fiscal da RFB & 427.501 \\
\hline Auditor fiscal do trabalho & 423.268 \\
\hline Delegado de Polícia Federal & 417.416 \\
\hline Perito criminal & 411.799 \\
\hline Advogado da união & 409.008 \\
\hline Diplomata & 396.719 \\
\hline Inspetor da CVM & 381.805 \\
\hline Médico do Dnit - 40h & 377.040 \\
\hline Técnico de planejamento & 368.983 \\
\hline Quadro suplementar em extinção da Advocacia-Geral da União (AGU) & 363.958 \\
\hline Técnico Ipea - NS & 363.767 \\
\hline Analista da CVM & 360.774 \\
\hline Analista técnico da Susep & 357.549 \\
\hline Supervisor médico pericial - 20h & 355.148 \\
\hline Procurador federal - NS & 353.608 \\
\hline Especialista em políticas públicas e gestão (EPPGG) & 351.389 \\
\hline Analista de comércio exterior & 340.496 \\
\hline
\end{tabular}

Fonte: SGP/ME.

As carreiras mais bem remuneradas são as do Plano de Carreira do Banco Central, seguidas pelas da Área Jurídica (do Executivo, como a AGU), da Auditoria Federal e do Ciclo de Gestão. ${ }^{1}$ Somadas, as 10 mais bem remuneradas contam com 22 mil servidores e custam R $\$ 10$ bilhões ao ano - aproximadamente $12 \%$ do que é gasto com os 534 mil servidores efetivos ativos federais.

\footnotetext{
${ }^{1}$ Agrupamento de cargos de gestão do governo federal. Recuperado de http://ciclodegestao.org.br/index.php/sobre/quem-somos/
} 


\subsection{Tabelas Remuneratórias com Maior Aumento}

Nos últimos 15 anos (período de 2004 a 2019), houve um aumento real de 53\% na remuneração dos servidores federais, segundo dados da SGP/ME. No entanto, algumas tabelas remuneratórias observaram um aumento real de mais de $200 \%$. O Banco Mundial, no relatório Um ajuste justo, mostra que o aumento da massa salarial federal desde 1999 se deve ao aumento da remuneração, e não de servidores. Entre 1999 e 2015, o custo por servidor aumentou 7\% ao ano, enquanto o número de funcionários cresceu 2\%. Abaixo, a Tabela 5 apresenta as 20 tabelas remuneratórias com maior aumento desde 2008.

\section{TABELA 5 VINTE TABELAS REMUNERATÓRIAS COM MAIOR AUMENTO REAL DE REMUNERAÇÃO}

\begin{tabular}{|c|c|}
\hline Tabela remuneratória & Aumento (\%) \\
\hline Dnit - cargos especiais & $311 \%$ \\
\hline IBGE - nível intermediário & $278 \%$ \\
\hline Institutos Federais de Ensino Superior (Ifes) - Técnico adm. em educação (direta) & $262 \%$ \\
\hline Fundação Oswaldo Cruz (Fiocruz) - nível superior (doutorado) & $250 \%$ \\
\hline Civil das org. militares - doutor & $244 \%$ \\
\hline Dnit - agente & $240 \%$ \\
\hline Agências reguladores - nível superior & $237 \%$ \\
\hline Fundo Nacional de Desenvolvimento da Educação (FNDE) - nível superior (doutorado) & $229 \%$ \\
\hline IBGE - nível superior (doutorado) & $228 \%$ \\
\hline Superintendência Nacional de Previdência Complementar (Previc) - nível superior & $227 \%$ \\
\hline Dnit - nível superior & $227 \%$ \\
\hline Superintendência da Zona Franca de Manaus (Suframa) - nível superior & $226 \%$ \\
\hline Técnico de tecnologia militar & $219 \%$ \\
\hline Ministério da Agricultura, Pecuária e Abastecimento (Mapa) - Auxiliar de Laboratório & $216 \%$ \\
\hline Ifes - Médico & $212 \%$ \\
\hline Agências reguladoras - nível intermediário & $211 \%$ \\
\hline Previc - nível intermediário & $201 \%$ \\
\hline Seguro Social - agente ou técnico & $198 \%$ \\
\hline Assistente de chancelaria & $197 \%$ \\
\hline Fiocruz - nível intermediário & $188 \%$ \\
\hline
\end{tabular}

Fonte: SGP/ME. 
Os cargos especiais do Departamento Nacional de Infraestrutura de Transportes (Dnit) obtiveram o maior aumento, de $311 \%$, seguidos pelos de nível intermediário do IBGE (278\%). Nesse gráfico, há uma concentração de entidades, com alguns que aparecem mais de uma vez, como o próprio Dnit (três vezes) e o IBGE (duas vezes). Isso pode indicar que os órgãos (ou as entidades) dão aumentos generosos para várias tabelas remuneratórias de uma vez.

\subsection{Idade de Aposentadoria e Topo de Carreira}

Outro ponto a ser considerado é a chegada ao topo de carreira. Nos últimos anos, houve mudanças na estrutura, de modo que em várias delas os servidores chegam mais cedo ao topo. Esse é um ponto importante, pois estar no topo representa, em média, ter remuneração $49 \%$ maior do que no início de carreira, segundo dados da SGP/ME. Além disso, o servidor pode não ter uma motivação para continuar trabalhando com a mesma performance. Um exemplo é fornecido em Klein e Mascarenhas (2016), ao analisarem a carreira de especialistas em políticas públicas e gestão governamental (EPPGG), sugerindo que a propensão à evasão da carreira pode estar associada à expectativa de evolução salarial no futuro. Esse problema pode se agravar com a reforma da previdência, que fará com que os servidores se aposentem mais tarde e, portanto, fiquem mais anos no topo de carreira.

Em média, segundo dados da SGP/ME e do Boletim Estatístico de Pessoal de 2017, os servidores públicos federais civis iniciam a carreira aos 33,7 anos e se aposentam aos 56,6 . Os de nível superior ingressam aos 35,2 e se aposentam, em média, aos 56,8; os de nível intermediário ingressam aos 30,6 e se aposentam aos 56,1; e os de nível auxiliar ingressam aos 34,5 e se aposentam aos 59,6.

Sobre a idade de chegada ao topo, a Figura 1 apresenta uma análise de carreiras do serviço público que não sofreram mudanças nos últimos 20 anos e que têm um número significativo de servidores. Nela, percebemos que, para essas carreiras, os servidores chegam ao topo usualmente entre 40 e 55 anos. Isso significa que uma grande parte estará em topo de carreira, se levarmos em consideração a idade de aposentadoria de 65 anos, com a Nova Previdência.

Servidores da Polícia Federal chegam mais rápido ao topo, passando por somente 4 níveis salariais - 41 anos para agente e 42 para delegado. Portanto, as carreiras da PF consistem essencialmente em 10 anos servindo em nível abaixo do topo, pouco mais de 10 no topo e aposentadoria com salário integral de topo de carreira. Percebe-se que isso não é sustentável nem responsável com os cofres públicos. Outro dado interessante que agrega à discussão é que $76 \%$ dos agentes da PF e $80 \%$ dos delegados estão no topo da carreira.

Por outro lado, a existência de poucos níveis não significa necessariamente chegada rápida ao topo. Um diplomata passa por somente seis níveis, mas chega ao topo, em média, só aos 61 anos. 


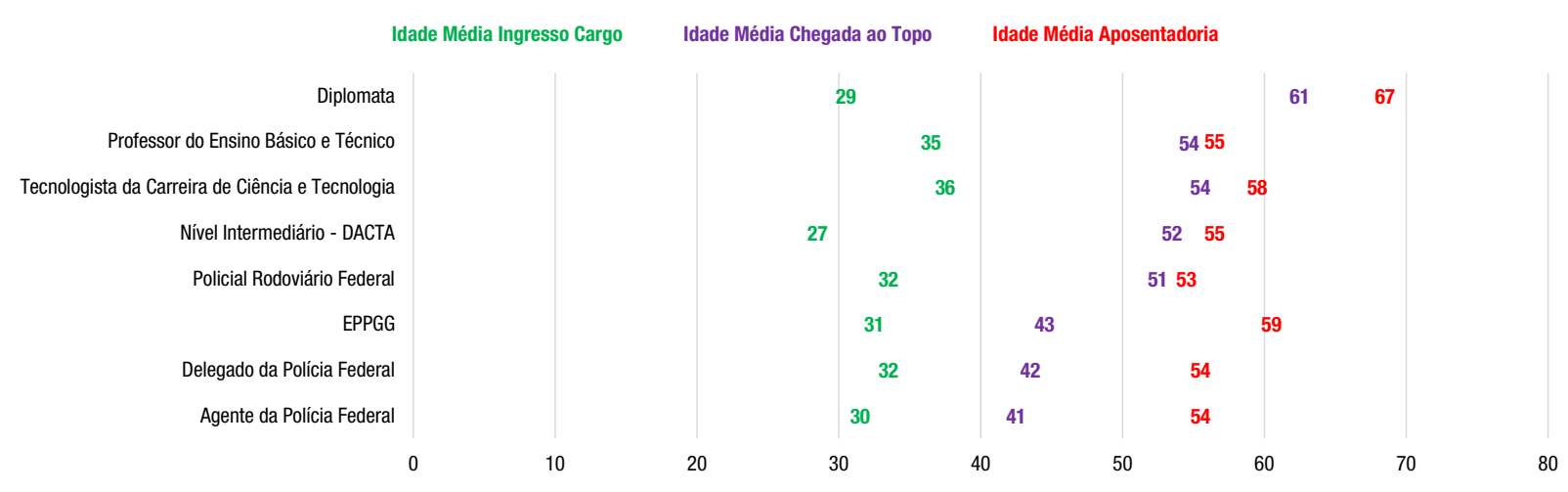

Fonte: SGP/ME.

Dados da SGP/ME mostram que, dos aproximadamente 530 mil servidores na base, 175 mil estão em topo de carreira (32.8\%). Dos servidores com custo ${ }^{2}$ total à união por trabalhador acima de R 300 mil (27 mil deles), 19 mil estão em topo de carreira (71\%). Assim, com essas condições, carreiras de maior remuneração também apresentam chegada mais rápida ao topo. É possível que elas tenham maior poder de barganha político, o que se traduz em regras de remuneração e ascensão mais generosas.

\section{ANÁLISE DE DADOS}

\subsection{Comparação com a Iniciativa Privada}

Nos últimos anos, desenvolveu-se extensa literatura no Brasil acerca do prêmio salarial públicoprivado federal. Braga, Firpo e Gonzaga (2009) indicam que a remuneração dos servidores é maior que a de trabalhadores, mas que essa vantagem decai conforme a escolaridade aumenta. Já Tenoury e Menezes-Filho (2017) indicam que o prêmio salarial público-privado federal aumentou de 28\% em 1999 para 93\% em 2015, com o crescimento do prêmio salarial associado ao período de maior quantidade de contratações nos anos 2000. Este artigo também avalia que o aumento do prêmio salarial é explicado por remunerações de servidores de média e alta instrução.

O Banco Mundial (2017) indica que o Brasil tem um dos maiores prêmios salariais do setor público no mundo, sobretudo na esfera federal - com prêmio de 67\%. Por fim, Carvalho (2020) indica que boa parte do prêmio salarial - público, não somente federal - está concentrado em algumas ocupações, em geral carreiras do direito, de administração e TIC. Dito isso, conduzimos uma análise de carreiras específicas abaixo, primeiramente com carreiras do direito e de administração.

\footnotetext{
${ }^{2}$ Inclui todas as despesas e os benefícios possíveis, além da remuneração bruta.
} 
No Gráfico 4, temos uma comparação do salário de servidores com o salário-mínimo e máximo de trabalhadores da iniciativa privada de cargos semelhantes nas carreiras públicas em que existe um cargo similar na iniciativa privada. Os dados são da SGP/ME, para servidores públicos, e do guia de salários de 2019 da Robert Half, para a iniciativa privada. Vemos que a diferença é grande em todos os casos, com um prêmio salarial do servidor público.

\section{GRÁFICO 4 COMPARAÇÃO DA REMUNERAÇÃO MÉDIA ANUAL ENTRE SERVIDORES PÚBLICOS E} PRIVADOS (2018)

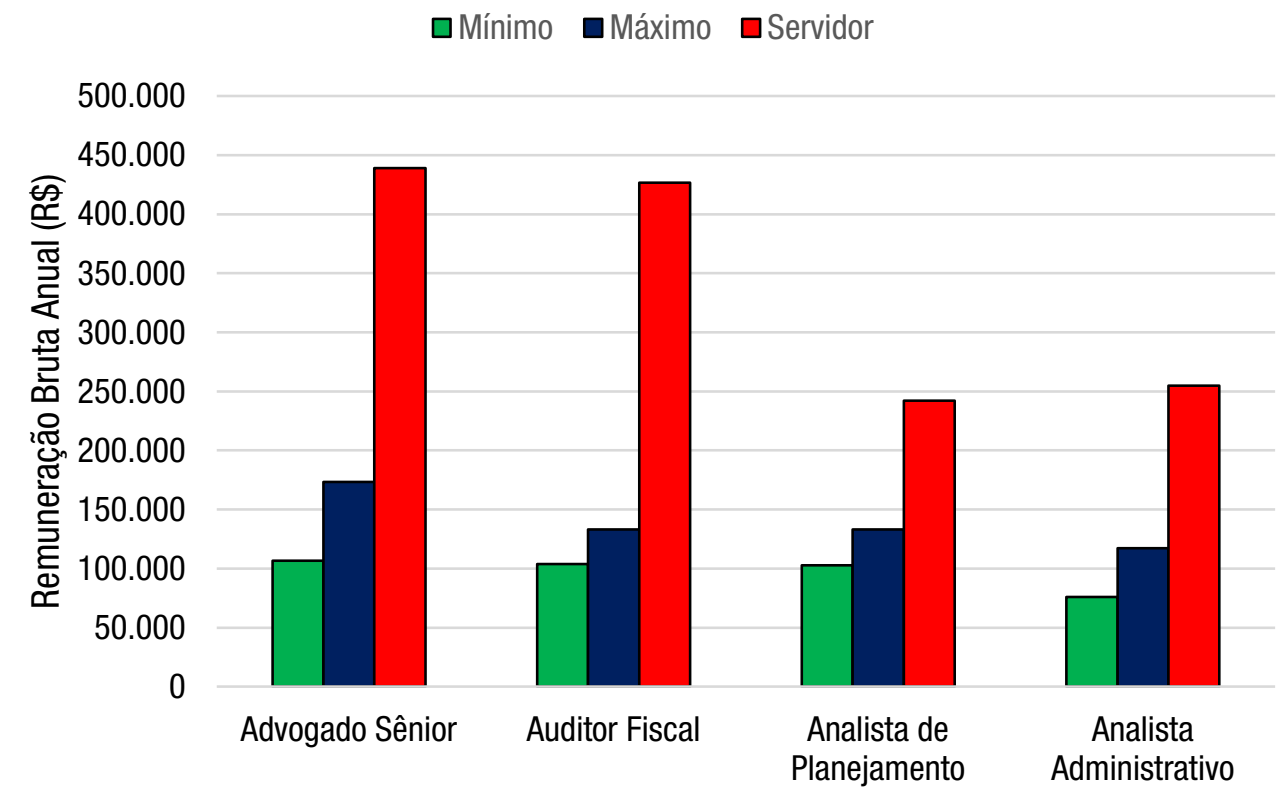

* Advogado sênior: advogado sênior de empresas de grande porte versus advogado da união.

** Auditor fiscal: analista contábil/fiscal sênior de empresas de grande porte versus auditor fiscal da RFB.

$* * *$ Analista de planejamento: analista de planejamento/controladoria sênior de empresa de grande porte versus analista de planejamento.

**** Analista administrativo: analista de recursos humanos (business partner) de empresa de grande porte versus analista administrativo das agências reguladoras.

$\star * * * \star$ Salários mensais da iniciativa privada multiplicados por 13,33 para torná-lo anual, considerando $13^{\circ}$ e férias.

Fonte: Elaborado pelo autor com dados da SGP/ME e do Guia Salarial da Robert Half.

\subsection{Comparação entre ministérios}

Abaixo, segue uma análise comparando a remuneração de várias carreiras do serviço público e o salário mediano recebido por ministério. Comparamos a remuneração entre motoristas (Gráfico 5), agentes administrativos (Gráfico 6) e agentes de portaria (Gráfico 7), com filtro em ministérios que tenham mais de 20 servidores na função. É de imaginar que, dentro da carreira, os servidores executam serviços similares, não devendo haver grande diferença nos salários recebidos.

O que vemos, no entanto, é que há certa variação na remuneração, com o Ministério da Infraestrutura e o Ministério de Minas e Energia usualmente pagando os maiores salários. No caso de motoristas, a média recebida gira em torno de R \$ 5,5 mil, enquanto o Ministério da Infraestrutura paga, em média, quase R 9 mil para seus motoristas. 


\section{GRÁFICO 5 SALÁRIO MEDIANO DE MOTORISTAS POR MINISTÉRIO}

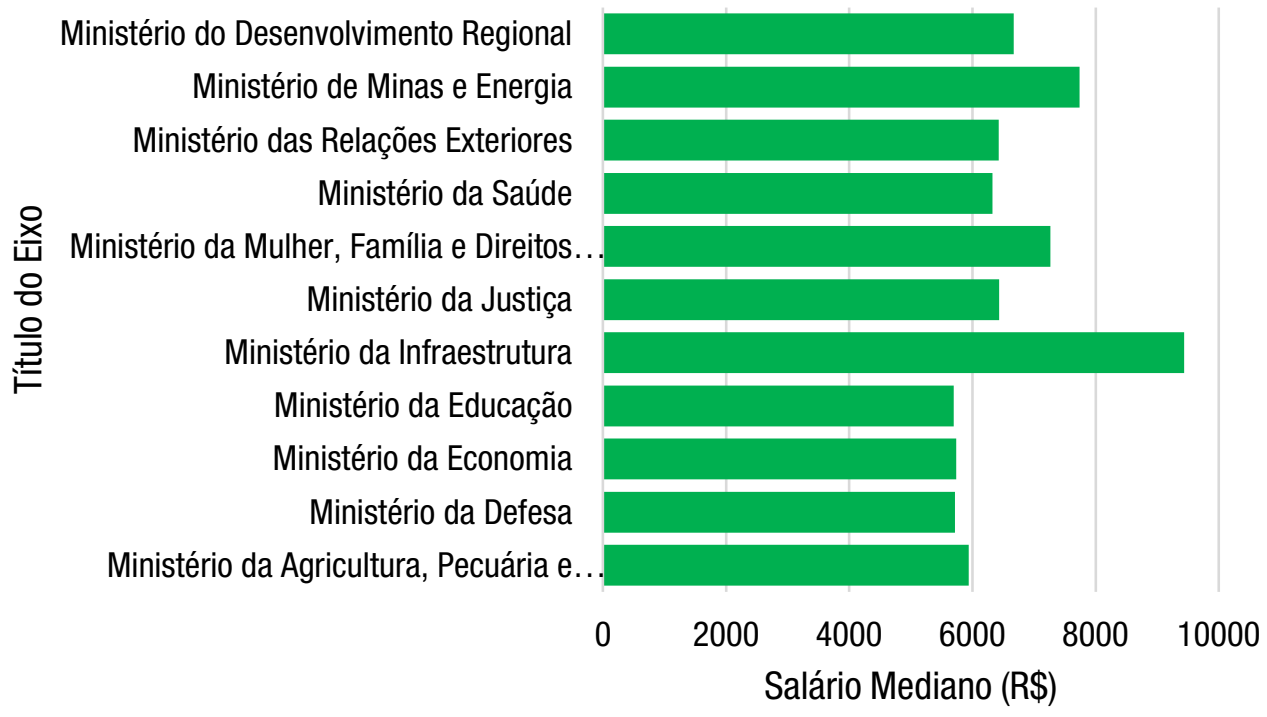

Fonte: Elaborado pelo autor com dados do Portal da Transparência.

\section{GRÁFICO 6 SALÁRIO MEDIANO DE AGENTES ADMINISTRATIVOS POR MINISTÉRIO}

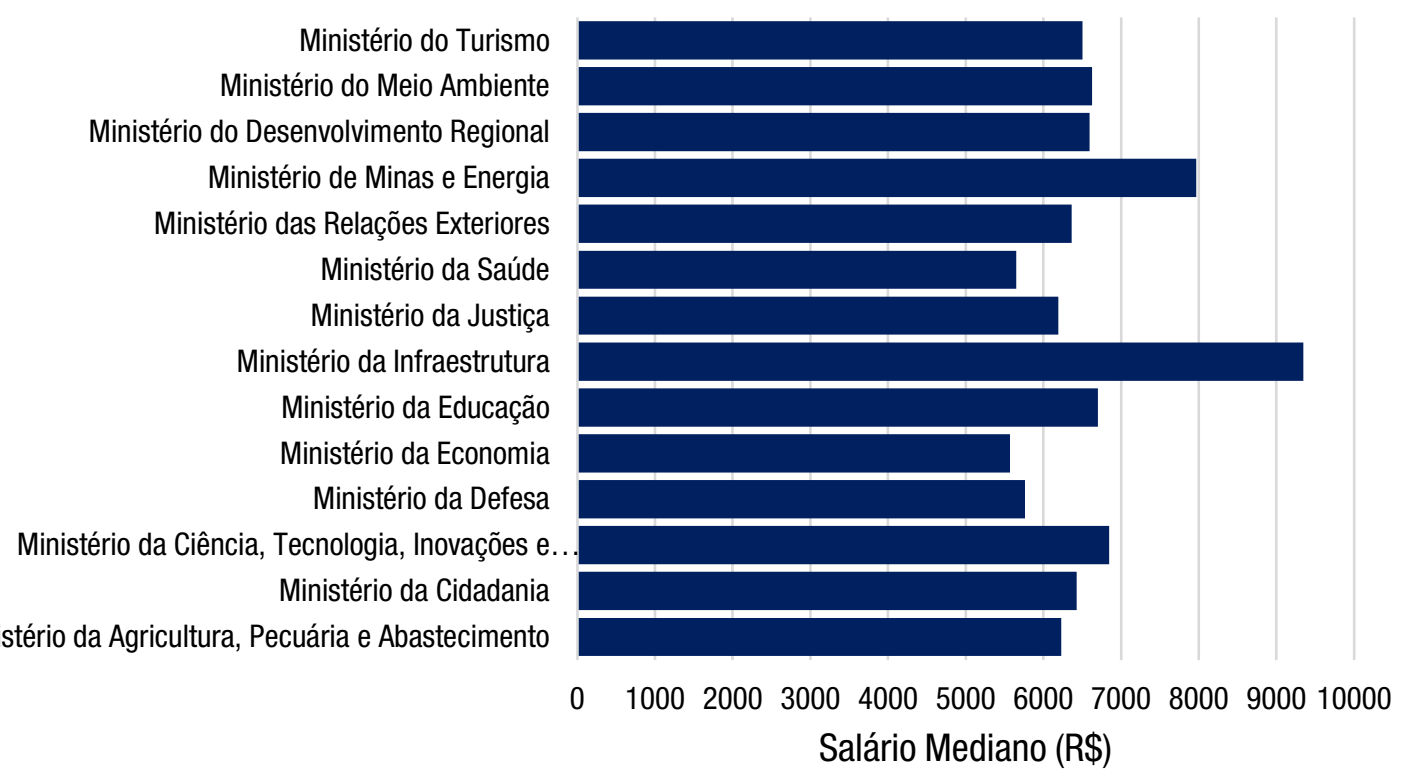

Fonte: Elaborado pelo autor com dados do Portal da Transparência. 


\section{GRÁFICO 7 SALÁRIO MEDIANO DE AGENTES DE PORTARIA POR MINISTÉRIO}

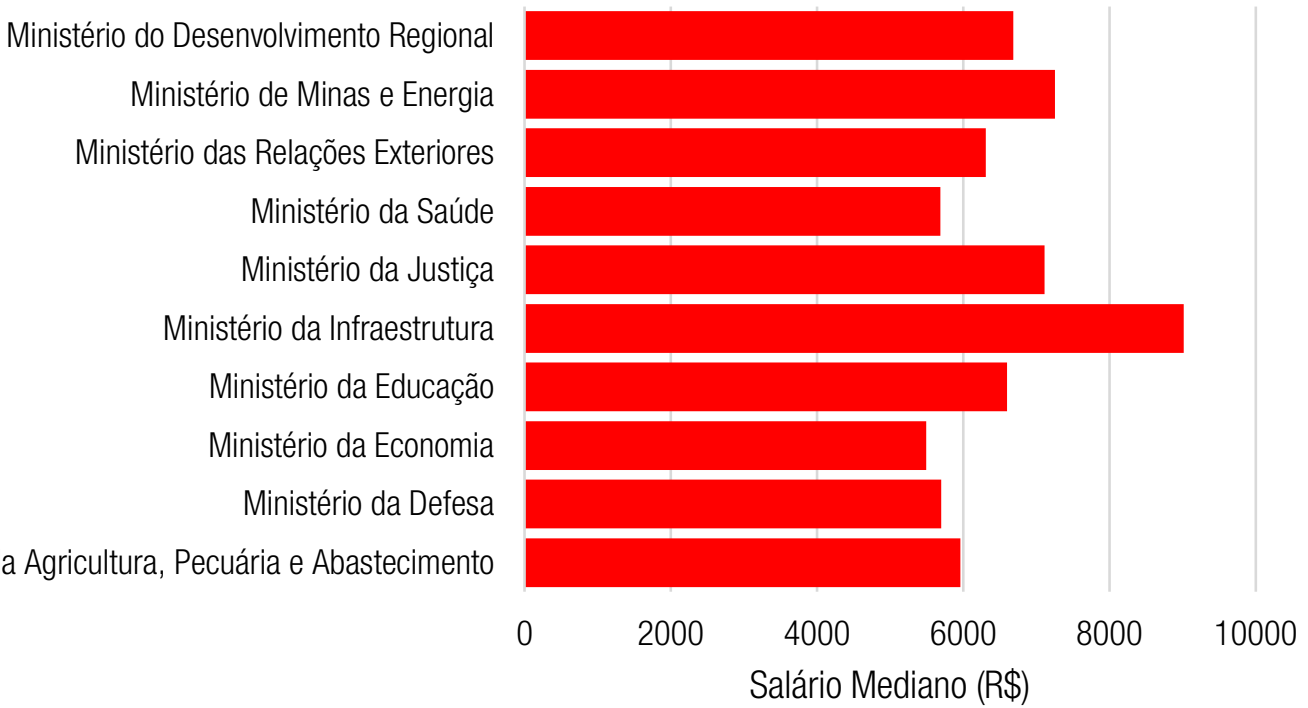

Fonte: Elaborado pelo autor com dados do Portal da Transparência.

Também calculamos o prêmio salarial de ministérios. Karpowicz e Soto (2018) já fizeram uma interessante análise a respeito, e complementamos aqui com o exame da nova composição ministerial do presente governo. Rodamos uma regressão do logaritmo da remuneração bruta do servidor por ministério, controlado por cargo, estado e longevidade no serviço público (em anos). É importante frisar que, quando se diz cargo, trata-se de função, e não de carreira. Por exemplo, um motorista do Ministério da Saúde está numa carreira diferente de um motorista de agência reguladora, portanto esses servidores estão em tabelas remuneratórias distintas, apesar de realizarem a mesma função. A variável removida é o Ministério do Desenvolvimento Regional, de modo que o prêmio salarial é relativo a esse ministério, que tem remuneração perto da média. Desse modo, teremos uma regressão como a seguinte:

$$
\begin{gathered}
\log \left(Y_{i}\right)=M I N_{1 i} \beta_{1}+\ldots+M I N_{n i} \beta_{n}+T_{i} \delta+U F_{1 i} \alpha_{1}+\ldots+U F_{k i} \alpha_{k}+, \\
Z_{1 i} \gamma_{1}+\ldots+Z_{m i} \gamma_{m}+\epsilon_{i},
\end{gathered}
$$

em que $Y_{i}$ é a remuneração do servidor i, $M I N_{A i}$ é igual a 1 para o ministério A no qual está alocado, $T_{i}$ é o número de anos do servidor no serviço público, $U F_{B i}$ é igual a 1 para a unidade da federação $\mathrm{B}$ onde o servidor trabalha e $Z_{C i}$ é igual a 1 para o cargo $C$ do servidor.

Analisando os resultados da regressão, que estão indicados em detalhes no Apêndice, podemos ver que os coeficientes são, em boa parte, estatisticamente significantes ao nível de $1 \%$. Ou seja, a remuneração do servidor pode variar de maneira significativa, dependendo do ministério no qual trabalha. Por exemplo, trabalhar no Ministério da Infraestrutura ou no da Mulher, Família e Direitos Humanos pode representar um ganho de $20 \%$ na remuneração, se comparado a trabalhar no Ministério do Desenvolvimento Regional. Esse cenário dificulta uma tentativa de padronização 
e racionalização do serviço público, contribuindo para um panorama de desorganização entre os cargos da esfera pública federal.

O Gráfico 8 mostra mais claramente a diferença de remuneração entre ministérios distintos para um servidor ainda sem 1 ano de experiência. Podemos ver que o Ministério da Mulher, Família e Direitos Humanos é o de maior remuneração, enquanto o do Meio Ambiente tem a menor. Além disso, a posição do Ministério da Infraestrutura, segundo maior prêmio salarial, pode ter sido influenciada pelo aumento salarial para servidores do Dnit, com tabelas remuneratórias que obtiveram aumento real maiores do que $240 \%$ no período de 2003 a 2018, como evidenciado na seção 2.5 .

\section{GRÁFICO 8 DIFERENCIAL DE REMUNERAÇÃO POR MINISTÉRIO}

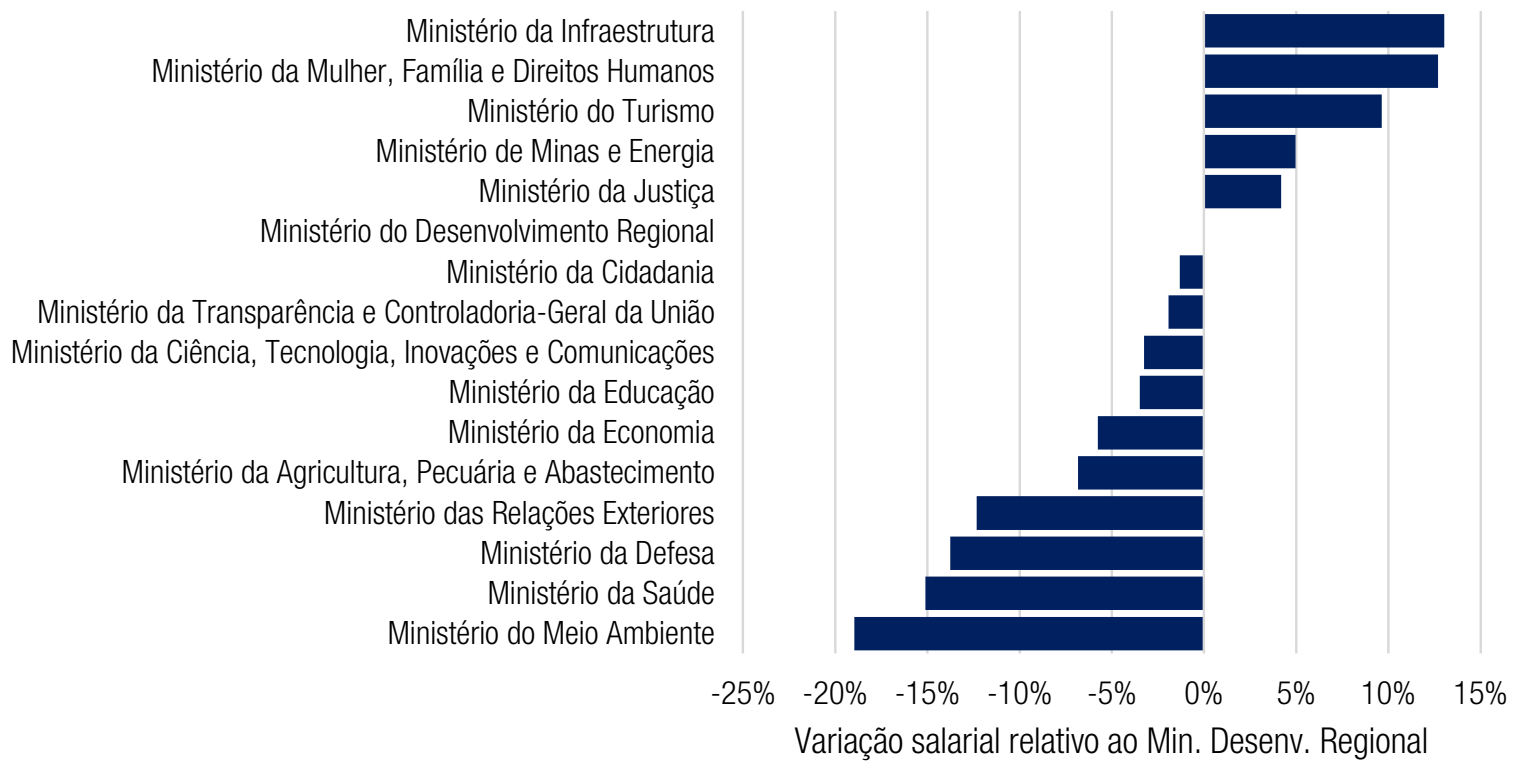

Fonte: Elaborado pelo autor com dados do Portal da Transparência.

\subsection{Administração indireta}

Outra questão importante é sobre a administração indireta, que engloba fundações e autarquias. Como avalia Martins (1995), a administração indireta teve, ao longo do tempo, um processo administrativo diferente da direta, com objetivos e métodos contrastantes. $\mathrm{O}$ autor ainda indica uma explosão no número de fundações, autarquias e empresas públicas entre 1966 e 1976, com aproximadamente 340 dessas entidades criadas nesse período. Portanto, num contexto de reforma administrativa, é interessante avaliar a estrutura e a diferença salarial entre as administrações.

Então, rodamos uma regressão de remuneração, controlando por ministério, unidade federativa (UF), função e longevidade no serviço público, como na seção anterior. O que vemos nos resultados da regressão na Tabela 6 é que, de fato, a administração indireta tem, em média, remuneração maior, 
controlando por ministério, função e UF. O coeficiente é estatisticamente significante ao nível de 1\% e relativamente grande (0.091), indicando que trabalhar na administração indireta representa um ganho de cerca de $9 \%$ na remuneração.

\section{TABELA 6 COEFICIENTES DA REGRESSÃO SOBRE 0 LOGARITMO DA REMUNERAÇÃO DOS SERVIDORES}

\begin{tabular}{lc} 
& $\log$ (remuneração bruta) \\
\hline Administração indireta & $0.094^{* *+*}$ \\
& $(0.002)$ \\
Anos na carreira & $0.014^{* * *}$ \\
& $(0.000)$ \\
Controle de ministério & Sim \\
Controle de função & Sim \\
Controle de UF & Sim \\
Observações & 445,249 \\
R2 Ajustado & 0.804
\end{tabular}

Notas:

*** Significante ao nível de $1 \%$.

** Significante ao nível de $5 \%$.

* Significante ao nível de $10 \%$.

Fonte: Elaborada pelo autor.

Podemos comparar salários de certos cargos para termos um exemplo mais claro do resultado acima. No Gráfico 9, comparamos a remuneração de servidores da administração direta e indireta das mesmas carreiras de antes: motorista, agente administrativo e agente de portaria. À esquerda, temos a comparação da mediana da remuneração; à direita, a comparação da remuneração média.

A remuneração mediana nessas funções é similar e até maior na administração direta. Porém, quando se leva a remuneração média em consideração, a administração indireta salta à frente. Isso indica que, provavelmente, existem servidores na administração indireta que recebem bem mais do que a média. De fato, os 30 maiores salários de motoristas são de administração indireta, majoritariamente de agências reguladoras, com remuneração entre $\mathrm{R} \$ 10$ e 13 mil. 


\section{GRÁFICO 9 COMPARAÇÃO DA REMUNERAÇÃO ENTRE ADMINISTRAÇÃO DIRETA E INDIRETA}
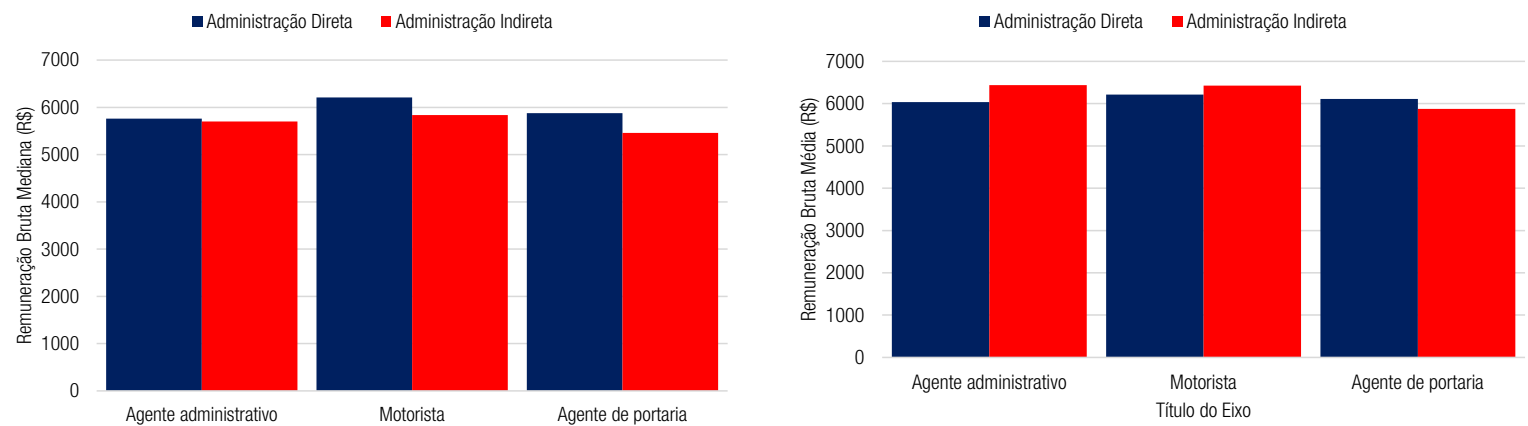

Fonte: Elaborado pelo autor com dados do Portal da Transparência.

$\mathrm{Na}$ Tabela 7, seguem as maiores remunerações por entidade da administração indireta - com mais de 30 servidores registrados no Portal da Transparência. As maiores remunerações se encontram no Ipea e no Banco Central (Bacen), seguidas por Superintendência de Seguros Privados (Susep), Comissão de Valores Mobiliados (CVM) e agências reguladoras, todos com média próxima ou acima de R\$20 mil mensais. Possivelmente, isso é explicado pela maior quantidade de servidores com pósgraduação no Ipea e no Bacen.

\section{TABELA 7 MAIORES REMUNERAÇÕES MEDIANAS ENTRE ENTIDADES DA ADMINISTRAÇÃO INDIRETA}

\begin{tabular}{lc} 
Entidade & Remuneração bruta mensal mediana (R\$) \\
\hline Banco Central do Brasil & 27827 \\
Instituto de Pesquisa Econômica Aplicada & 27827 \\
Superintendência de Seguros Privados & 25363 \\
Comissão de Valores Mobiliários & 24997 \\
Agência Nacional de Águas & 20078 \\
Agência Nacional de Saúde Suplementar & 19574 \\
Agência Nacional do Petróleo, Gás Natural e Biocombustíveis & 18906 \\
Agência Nacional de Energia Elétrica & 18708 \\
Agência Nacional de Telecomunicações & 18583 \\
Agência Nacional de Aviação Civil & 18214
\end{tabular}

Fonte: Elaborada pelo autor com dados do Portal da Transparência. 
Para fazermos uma análise mais detalhada sobre o diferencial de remuneração, podemos dividir a administração indireta entre os tipos de entidades que a constituem. Neste artigo, utilizamos as denominações "autarquias", "fundações públicas", "agências reguladoras", "institutos federais" e "universidades federais". Vale dizer que agências reguladoras, institutos federais e universidades federais são autarquias de regime especial, como explicado em Carvalho (2015, p. 498) e expresso em leis, como a Lei no 5.540/1968 - para universidades e estabelecimentos de ensino - ou a Lei no 9.427/1996 - para a Agência Nacional de Energia Elétrica (Aneel). Logo, é válido analisar tais agrupamentos de entidades separadamente de autarquias ditas comuns. No entanto, cabe dizer que há outras autarquias de regime especial, como o Banco Central. Mas, tendo em vista uma análise estatística mais enxuta, analisamos apenas agrupamentos de entidades separadamente.

Olhando a distribuição de remuneração de agentes administrativos no Gráfico 10, vemos que a remuneração bruta nas agências reguladoras é majoritariamente acima de $\mathrm{R} \$ 10$ mil, de modo que esses servidores recebem um salário, em média, maior que os de outros tipos de entidade. No gráfico não constam universidades federais ou institutos federais, pois não têm agentes administrativos (nessa denominação).

\section{GRÁFICO 10 DISTRIBUIÇÃO DA REMUNERAÇÃO DE AGENTES ADMINISTRATIVOS POR TIPO DE ENTIDADE}

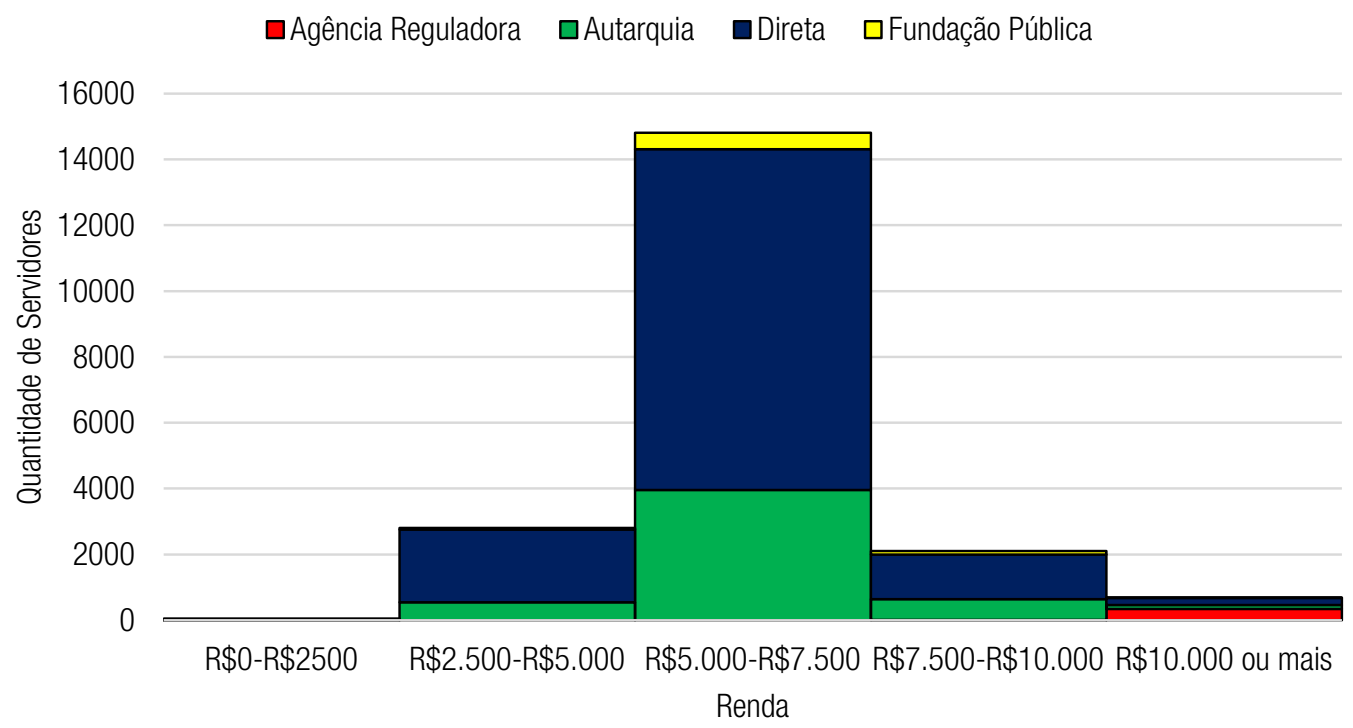

Fonte: Elaborado pelo autor com dados do Portal da Transparência.

Para uma medida mais pragmática do prêmio salarial da administração indireta, realizamos uma regressão por tipo de entidade, controlando por ministério/órgão superior, função e UF. A variável dummy correspondente à administração direta foi a escolhida para ser removida, de modo que os coeficientes apresentados são relativos à administração direta. É possível ver na Tabela 8 que o prêmio salarial das agências reguladoras é grande, enquanto os outros tipos de entidade têm um prêmio salarial entre 5\% e 15\%, com relação à administração direta. Todos os coeficientes são estatisticamente significantes em nível de $1 \%$. 


\section{TABELA 8}

COEFICIENTES DA REGRESSÃO SOBRE O LOGARITMO DA REMUNERAÇÃO DOS SERVIDORES

\begin{tabular}{|c|c|}
\hline & $\log$ (remuneração bruta) \\
\hline \multirow[t]{2}{*}{ Agência reguladora } & $0.540^{+\infty * x}$ \\
\hline & $(0.006)$ \\
\hline \multirow[t]{2}{*}{ Autarquia } & $0.068^{+*+x}$ \\
\hline & $(0.003)$ \\
\hline \multirow[t]{2}{*}{ Fundação pública } & $0.054^{*+*}$ \\
\hline & $(0.004)$ \\
\hline \multirow[t]{2}{*}{ Instituto federal } & $0.088^{+* x+}$ \\
\hline & $(0.008)$ \\
\hline \multirow[t]{2}{*}{ Universidade federal } & $0.094^{*+*}$ \\
\hline & $(0.008)$ \\
\hline \multirow[t]{2}{*}{ Anos na carreira } & $0.014^{4+* x}$ \\
\hline & $(0.000)$ \\
\hline Controle de ministério & Sim \\
\hline Controle de função & $\operatorname{Sim}$ \\
\hline Controle de UF & $\operatorname{Sim}$ \\
\hline Observações & 445,249 \\
\hline $\mathrm{R}^{2}$ ajustado & 0.806 \\
\hline
\end{tabular}

Fonte: Elaborada pelo autor.

A diferença, portanto, existe e é significativa. Carvalho (2011) já comenta de maneira mais ampla que há tal disparidade na remuneração, favorecendo o núcleo duro do governo: defesa jurídica do Estado (procuradores e advogados), tributária (auditores federais) e Polícia Federal, assim como agências reguladoras. Além disso, algumas carreiras e entidades têm maior poder de barganha e conseguem levar suas demandas para o governo com mais eficiência.

Carvalho (2011) ainda argumenta que existe um "efeito transbordamento" e que reajustes a cargos-chave de uma entidade levam a reajustes à entidade como um todo, o que aumenta o custo do servidor para a união e ajuda a explicar o diferencial de salários para a mesma função. Isso vai ao encontro das observações da seção 2.5, em que é indicado que os maiores aumentos são concentrados em certas entidades da administração indireta. Por fim, isso ocorre não somente dentro do Executivo, mas entre poderes. Servidores do Legislativo de certos cargos recebem muito mais que seus colegas do Executivo, mas uma análise mais profunda desse fenômeno está fora do escopo deste artigo. 


\section{PROCICLICALIDADE}

Um último ponto a ser feito é sobre a prociclicalidade da despesa com pessoal ativo civil do Executivo federal. O conceito de prociclicalidade nas contas públicas começou a ser estudado com foco na América Latina por Gavin e Perotti (1997), que observaram que os governos latino-americanos tendem a gastar muito em tempos econômicos favoráveis e a cortar brutalmente gastos durante recessões.

Temos 2 possíveis explicações para tal fenômeno. Gavin e Perotti (1997) indicam que uma possibilidade é que governos latino-americanos, como são menos estáveis do que os de países desenvolvidos, têm menos capacidade de pegar empréstimos em tempos de recessão e se veem forçados a cortar gastos - essa explicação é chamada de borrowing constraint. Outra possibilidade, expressa por Alesina, Campante e Tabellini (2008), é que a população não confia em governos democráticos corruptos e, portanto, demanda que receitas provenientes de ventos econômicos favoráveis sejam gastas o mais rápido possível, a fim de evitar a apropriação das receitas por agentes governamentais. Assim, o governo tem menor capacidade de investimento no momento de uma recessão e se vê forçado a cortar gastos.

A seguir, analisaremos a prociclicalidade das despesas com pessoal ativo civil do governo federal desde 1996 e tentaremos fornecer possíveis explicações para o fenômeno. No Gráfico 11, podemos ver a taxa de crescimento real de despesas com pessoal e o hiato do Produto Interno Bruto (PIB) brasileiro. O hiato utilizado vem de cálculo do Ipea, indicado nas Cartas de Conjuntura.

\section{GRÁFICO 11 TAXA DE CRESCIMENTO COM RELAÇÃO AO ANO ANTERIOR DA DESPESA COM PESSOAL ATIVO CIVIL DO EXECUTIVO FEDERAL E HIATO DO PIB}

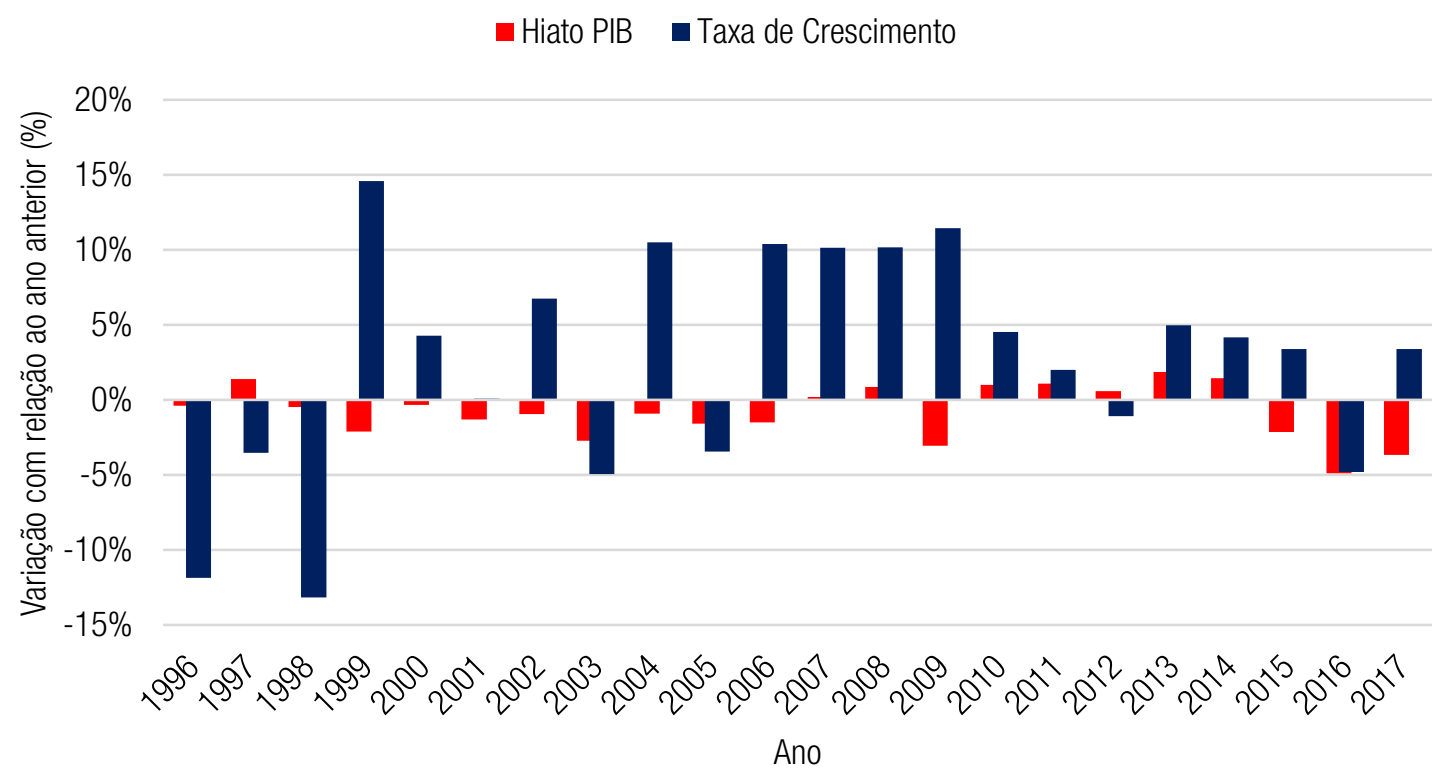

Fonte: Elaborado pelo autor com dados do Boletim Estatístico de Pessoal e da Carta de Conjuntura do Ipea. 
Agora, seguindo o método de Gavin e Perotti (1997), Alesina et al. (2008) e Mitchell, James e Wickham (2019), entre outros, rodamos uma regressão da taxa de crescimento das despesas $\left(W_{t}\right)$ sobre o hiato do PIB (Hiato_PIB ${ }_{t}$; a taxa de crescimento das despesas com pessoal civil ativo no ano anterior $\left(W_{t-1}\right)$; o hiato em termos de comércio, com dados do Banco Mundial), calculado de maneira semelhante ao hiato do produto (TOTGAP) ; a razão entre receitas de impostos federais do PIB do ano anterior, com dados do OECD.Stat, para a receita com impostos, e do IBGE, para o PIB (TaxToGDP $\left.{ }_{t-1}\right)$ :

$$
W_{t}=\text { Hiato_PIB }_{t} \beta_{1}+W_{t-1} \beta_{2}+\text { TOTGAP }_{t} \beta_{3}+\text { TaxToGDP } P_{t-1} \beta_{4}+\epsilon_{t} \text {. }
$$

O coeficiente de interesse é relativo ao hiato do PIB, $\beta_{1}$. Ele serve como medida de prociclicalidade, já que, se for positivo, indica que as despesas com pessoal civil ativo sobem em tempos de crescimento econômico e descem em tempos de recessão, acentuando o ciclo.

Os dados de taxa de crescimento de despesas reais com pessoal do Executivo federal civil são provenientes do Boletim Estatístico de Pessoal e ajustados pelo IPCA. Para a regressão, foram considerados os anos a partir de 1995 até 2017, após o plano real e com a infla1ção controlada, já que anos de alta inflação podem tornar a análise problemática - os governos tinham problemas em ajustar a remuneração dos servidores à inflação, e isso implicava uma grande volatilidade na taxa de crescimento das despesas reais. Além disso, a partir de 1995, os dados do Boletim Estatístico de Pessoal são mais completos e permitem uma análise mais detalhada. Assim, somente a partir de 1995 há maior continuidade e previsibilidade nas políticas de remuneração.

Vemos na Tabela 9 que o coeficiente de Hiato_PIB é positivo e significativo em nível de 10\%. Essa é uma indicação de que o comportamento das despesas com pessoal civil ativo do Executivo federal é procíclico, por mais que o número de observações seja bem restrito.

\section{TABELA 9 COEFICIENTES DA REGRESSÃO SOBRE A TAXA DE CRESCIMENTO DA DESPESA COM PESSOAL (1997-2017)}

$\begin{array}{cc} & \text { Taxa de crescimento } \\ \text { Hiato_PIB } & 1.262^{*} \\ & (0.731) \\ \text { W }_{\mathrm{t}-1} & -0.512^{* *} \\ & (0.255) \\ \text { TOTGAP } & -0.948^{* *} \\ & (0.439) \\ \text { TaxToGDP } & 2.843^{*+1} \\ & (0.936) \\ \text { Constante } & -0.356^{* *} \\ & (0.139) \\ \text { Observações } & 21 \\ \text { R }^{2} \text { ajustado } & 0.351\end{array}$

Fonte: Elaborada pelo autor. 
Uma questão que pode ser levantada é sobre inflação, cujo aumento corrói a despesa real com pessoal, e não a recessão em si. Na América Latina, ao contrário dos países desenvolvidos, a inflação tende a ser maior em tempos de recessão. De fato, vemos isso no Brasil desde 1997, de modo que a correlação entre o hiato do PIB e a inflação é -0.09. Adicionando inflação como uma variável independente na regressão, o coeficiente se mostrou próximo a zero e não alterou significativamente os resultados da regressão.

Para aprofundar a análise, podemos dividir em 2 variáveis: , o hiato do PIB quando este é positivo, e , o hiato do PIB quando este é negativo. Se o coeficiente de GAPBOOM for positivo, o crescimento do PIB estará relacionado a maiores gastos, um indicativo de prociclicalidade. Da mesma forma, se o coeficiente de GAPBUST for positivo, uma queda no PIB estará relacionada a corte de gastos. Ao dividir a variável do hiato, podemos determinar se a prociclicalidade é mais acentuada em tempos de crescimento ou em tempos de recessão.

O que vemos na Tabela 10 é que o coeficiente de GAPBUST é altamente positivo, de modo que a queda do PIB em 1\% durante uma recessão pode representar uma redução real de 1,39\% na despesa com pessoal civil ativo, indicando prociclicalidade. O mesmo não ocorre com o coeficiente de GAPBOOM, que também é positivo, mas de menor valor, de modo que o aumento em $1 \%$ do PIB acima do PIB potencial pode representar um aumento de $0,88 \%$ na despesa real com pessoal civil ativo. Os coeficientes não são significantes em níveis convencionais de confiança, já que o desvio padrão é alto - até porque a quantidade de observações é muito baixa.

\section{TABELA 10 COEFICIENTES DA REGRESSÃO SOBRE A TAXA DE CRESCIMENTO DA DESPESA COM PESSOAL (1997-2017)}

\begin{tabular}{|c|c|}
\hline & Taxa de crescimento \\
\hline \multirow[t]{2}{*}{$W_{t-1}$} & $-0.514^{* *}$ \\
\hline & $(0.259)$ \\
\hline \multirow[t]{2}{*}{ TOTGAP } & $-0.943^{* *}$ \\
\hline & $(0.456)$ \\
\hline \multirow{2}{*}{$\operatorname{TaxToGDP}_{\mathrm{t}-1}$} & $2.836^{*+*}$ \\
\hline & (0.985) \\
\hline \multirow[t]{2}{*}{ GAPBOOM } & 0.881 \\
\hline & $(2.176)$ \\
\hline \multirow[t]{2}{*}{ GAPBUST } & 1.390 \\
\hline & (1.182) \\
\hline \multirow[t]{2}{*}{ Constante } & $-0.352^{* *}$ \\
\hline & $(0.158)$ \\
\hline Observações & 21 \\
\hline $\mathrm{R}^{2}$ ajustado & 0.309 \\
\hline
\end{tabular}

Fonte: Elaborada pelo autor. 
Dado este experimento, há um indicativo de que a prociclicalidade de despesa com pessoal é liderada pelos tempos de recessão. Isso pode corroborar a teoria do borrowing constraint. De igual modo, vemos que o gasto também é procíclico durante expansões, de forma que a hipótese de falta de confiança do cidadão no governo pode ser plausível. É importante frisar que os dados não são estatisticamente significantes, em especial considerando o baixo número de observações.

\section{CONCLUSÃO}

Num momento de aperto das contas públicas no Brasil, é importante revermos as prioridades do governo federal, que atualmente conta com um orçamento enrijecido, com pouco espaço para investimentos. Dado que servidores públicos civis do Executivo federal de todos os níveis de escolaridade têm um prêmio salarial com relação à esfera privada - mais acentuado para servidores de nível superior, como documentado em Tenoury e Menezes-Filho (2017) -, uma revisão das carreiras deve ser prioridade, aproximando a remuneração de certas carreiras à realidade do país e racionalizando a progressão na carreira, com menos servidores no topo. Por mais que não seja o foco do artigo, uma revisão de carreiras também é importante para realinhar os incentivos dentro do funcionalismo público. Por exemplo, uma reforma direcionada às carreiras de educação pode reduzir o absenteísmo dos professores e levar a uma maior eficiência do ensino público, como indicado pelo Banco Mundial (2017).

Ademais, é preciso organizar a remuneração entre órgãos e entidades. Vimos que a remuneração varia consideravelmente entre ministérios e entre a administração direta e indireta. Isso dificulta a organização da esfera pública e contribui para o cenário de pouca eficiência que vemos no governo federal, como indicado pelo Banco Mundial (2017), que cita que o Brasil poderia economizar 0,3\% do PIB em serviços de saúde, $0,5 \%$ no ensino superior e $1 \%$ no ensino fundamental e médio, mantendo o mesmo nível de serviços. Também é importante rever a política de despesas com pessoal do Executivo para que seja mais anticíclica e atenue os efeitos de futuras recessões.

Pode-se considerar, em curto prazo, um congelamento de salários nos casos em que as distorções são mais agudas. Mas se trata de uma solução paliativa, como discutido na Introdução, pois o arcabouço institucional que permitiu tal distorção no primeiro lugar não seria alterado. Por fim, parte do problema pode ser equacionada com mudanças tributárias mais progressivas, haja vista que a maioria dos servidores civis do Executivo federal está no quintil de maior renda e que o sistema tributário brasileiro é notoriamente regressivo, como indicado em Gomes (2015).

Por fim, uma análise similar com relação ao Legislativo e ao Judiciário pode indicar possíveis fatores de melhora nesses poderes e contribuir para uma maior eficiência do Estado brasileiro como um todo. Por exemplo, como indicado em Guedes e Lopez (2019), a remuneração mediana do Poder Judiciário aumentou mais rapidamente do que as remunerações medianas do Executivo ou do Legislativo no período de 1986 a 2017. Uma análise mais aprofundada desse tópico seria muito bem-vinda. Ademais, uma investigação relativa às despesas com militares (ativos e inativos) seria importante para a correção de distorções, bem como uma pesquisa sobre outros entes federativos, por mais que se saiba que o prêmio salarial é menor em estados e, principalmente, em municípios, como indicado em Góes e Karpowicz (2017). 


\section{REFERÊNCIAS}

Alesina, A., Campante, F., \& Tabellini, G. (2008). Why is fiscal policy often procyclical? Journal of the European Economic Association, 6, 1006-1036.

Alesina, A., \& Tabellini, G. (2005, setembro). Why is fiscal policy often procyclical? (NBER Working Paper 11600). Cambridge, MA: National Bureau of Economic Research.

Banco Mundial. (2017). Um ajuste justo: análise da eficiência e equidade do gasto público no Brasil. Recuperado de http://documents. worldbank.org/curated/en/884871511196609355/ pdf/121480-REVISED-PORTUGUESE-BrazilPublic-Expenditure-Review-Overview-PortugueseFinal-revised.pdf

Braga, B., Firpo, S., \& Gonzaga, G. (2009). Escolaridade e diferencial de rendimentos entre o setor privado e o setor público no brasil. Pesquisa e Planejamento Econômico, 39, 431-464.

Bureau of Labor Statistics. (2018a). Occupational outlook handbook - lawyers. Recuperado de https:// www.bls.gov/ooh/legal/lawyers.htm\#tab-5

Bureau of Labor Statistics. (2018b). Occupational outlook handbook - police and detectives. Recuperado de www.bls.gov/ooh/protective-service/police-anddetectives.htm

Bureau of Labor Statistics. (2018c). Occupational outlook handbook - postsecondary teachers. Recuperado de www.bls.gov/ooh/educationtraining-and-library/postsecondary-teachers. htm\#tab-5

Bureau of Labor Statistics. (2018d). Occupational outlook handbook - tax examiners and collectors, and revenue agents. Recuperado de www.bls.gov/ ooh/business-and-financial/tax-examiners-andcollectors-and-revenue-agents.htm\#tab-5

Cardoso, J., \& Nogueira, R. (2017). Transformações da ocupação no setor público federal brasileiro: tendências recentes e questões a futuro. In Instituto de Pesquisa Econômica Aplicada (Org.), Boletim de Análise Político-Institucional. Brasília, DF: Autor.

Carvalho, E. (2011). Salários e política de vencimentos no Poder Executivo federal na primeira década de 2000. In J. C. Cardoso Junior (Org.), Burocracia e ocupação no setor público brasileiro (pp. 133-180). Brasília, DF: Ipea.
Carvalho, J. S. (2015). Manual de direito administrativo (28a ed.). São Paulo, SP: Editora Atlas.

Carvalho, S. (2020). Qualificando o debate sobre diferenciais de remuneração entre setores público e privado no Brasil (Cadernos da Reforma Administrativa, 5). Brasília, DF: Fórum Nacional Permanente de Carreiras Típicas de Estado.

Cavalcante, P., \& Carvalho, P. (2017). Profissionalização da burocracia federal brasileira (1995-2014): avanços e dilemas. Revista de Administração Pública, 51(1), 1-26.

Consejo de Defensa del Estado. (2019). Dotación de planta: diciembre 2017. Recuperado de www.cde. cl/transparencia/2017/per_planta_diciembre.html

Forni, L., \& Novta, N. (2014, outubro). Public employment and compensation reform during times of fiscal consolidation (IMF Working Paper No. 14/192). Washington, DC: International Monetary Fund.

Francisco, D. (2015). Gestão do trabalho e valorização profissional: a questão da sobrequalificação para o trabalhador técnico do SUS (Dissertação de Mestrado). Fundação Oswaldo Cruz, Rio de Janeiro, RJ.

Fundo Monetário Internacional. (2016). Government finance statistics. Recuperado de https://data.imf. org/GFS

Gavin, M., \& Perotti, R. (1997). Fiscal policy in Latin America. NBER Macroeconomics Annual 1997, 12, 11-72.

Góes, C., \& Karpowicz, I. (2017, setembro). Inequality in Brazil: a regional perspective (IMF Working Paper No. 17/225). Washington, DC: International Monetary Fund.

Gomes, M. (2015). As distorções de uma carga tributária regressiva. Desafios do desenvolvimento. Recuperado de www.ipea.gov.br/desafios/ index.php?option=com_content\&view $=$ article \&id $=3233 \&$ catid $=30 \&$ Itemid $=41$

Gonçalves, J. M., Neto. (2017). Sobrequalificação $e$ atitudes no trabalho entre servidores públicos (Dissertação de Mestrado). Universidade de Brasília, Brasília, DF.

Guedes, E., \& Lopez, F. (2019). Três Décadas de Evolução do Funcionalismo no Brasil (1986-2017): Atlas do Estado Brasileiro. Brasília, DF: Instituto de Pesquisa Econômica Aplicada. 
Instituto Brasileiro de Geografia e Estatística. (2019). PNAD Contínua: rendimento de todas as fontes. Recuperado de www.ibge.gov.br/ estatisticas/sociais/trabalho/17270-pnad-continua. html? edicao $=27257 \& \mathrm{t}=$ sobre

Jaimovich, D., \& Panizza, U. (2007, março). Procyclicality or Reverse Causality? (IDB Working Paper Series 599). Washington, DC: Inter-American Development Bank.

Karpowicz, I., \& Soto, M. (2018, outubro). Rightsizing Brazil's public-sector wage bill (IMF Working Paper No. 18/225). Washington, DC: International Monetary Fund.

Klein, F., \& Mascarenhas, A. (2016). Motivação, satisfação profissional e evasão no serviço público: o caso da carreira de especialistas em políticas públicas e gestão governamental. Revista de Administração Pública, 50(1), 17-39.

Martins, L. (1995). Reforma da administração pública e cultura política no brasil: uma visão geral. Cadernos da Enap, 8, 9-39.

Mitchell, W., James, R., \& Wickham, A. M. (2019, maio). Government wage bill management and civil service reform in the eastern Caribbean currency union (IMF Working Paper No. 19/110). Washington, DC: International Monetary Fund.

Organização para a Cooperação e o Desenvolvimento Econômico. (2015). Government at a Glance 2015. Paris, France: OECD Publishing. Recuperado de https://doi.org/10.1787/22214399

Organização para a Cooperação e o Desenvolvimento Econômico. (2016). OECD surveyon the compensation of employees in central/federal governments.

Organização para a Cooperação e o Desenvolvimento Econômico. (2017). Government at a Glance 2017.
Paris, France: OECD Publishing. Recuperado de https://doi.org/10.1787/22214399

Organização para a Cooperação e o Desenvolvimento Econômico. (2018). Revenue statistics 2018 tax revenue trends in the OECD. Paris, France: OECD Publishing.

Organização para a Cooperação e o Desenvolvimento Econômico. (2019). Purchasing power parities (PPP). Paris, France: OECD Publishing. Recuperado de https://data.oecd.org/conversion/purchasingpower-parities-ppp.htm

Palotti, P., \& Freire, A. (2015). Perfil, composição e remuneração dos servidores públicos federais: trajetória recente e tendências observadas. In Anais do $8^{\circ}$ Congresso CONSAD de Gestão Pública, Brasília, DF.

Policía de Investigaciones. (2019). Escala de remuneraciones. Recuperado de http:// gobiernotransparente.investigaciones.cl/ transparencia/2015/remuneraciones/planta/1_ planta_de_oficiales/of_policiales/per_ remuneraciones.html

Portal da Transparência. (2019). Servidores Civis e Militares do Executivo Federal. Recuperado de www. portaltransparencia.gov.br/download-de-dados/ servidores

Servicio de Impuestos Internos. (2019). Dotación de planta: marzo 2019. Recuperado de www.sii.cl/ transparencia/2019/per_planta_mar.html

Tenoury, G., \& Menezes-Filho (2017). A evolução do diferencial salarial público-privado no Brasil. São Paulo, SP: Insper.

Universidad de Chile. (2019). Dotación de planta: junio 2019. Recuperado de http://web.uchile.cl/ transparencia/plantajun2019ab.html

\section{Enzo Bastos Profili}

https://orcid.org/0000-0001-6209-5920

Bacharel em economia pela Northwestern University. E-mail: enzoprofili2021@u.northwestern.edu 


\section{APÊNDICE}

\section{Coeficientes de regressão ministerial}

\section{TABELA 11 COEFICIENTES DA REGRESSÃO SOBRE 0 LOGARITMO DA REMUNERAÇÃO DOS SERVIDORES}

\begin{tabular}{|c|c|c|}
\hline & \multicolumn{2}{|c|}{ Log (Remuneração Bruta) } \\
\hline & (1) & (2) \\
\hline \multirow[t]{2}{*}{ Ministério da Agricultura, Pecuária e Abastecimento } & $-0.055^{* * *}$ & $0.129^{*+* x}$ \\
\hline & $(0.006)$ & $(0.011)$ \\
\hline \multirow[t]{2}{*}{ Ministério da Cidadania } & $-0.042^{* * *}$ & $-0.075^{\star * *}$ \\
\hline & $(0.011)$ & $(0.013)$ \\
\hline \multirow[t]{2}{*}{ Ministério da Ciência, Tecnologia, Inovações e Comunicações } & $-0.035^{* *+}$ & $0.381^{*+*+}$ \\
\hline & $(0.006)$ & $(0.011)$ \\
\hline \multirow[t]{2}{*}{ Ministério da Defesa } & $-0.138^{* * *+}$ & $-0.195^{+*+x}$ \\
\hline & $(0.005)$ & $(0.010)$ \\
\hline \multirow[t]{2}{*}{ Ministério da Economia } & $-0.059^{* * *+}$ & $0.351^{*+*}$ \\
\hline & $(0.005)$ & $(0.010)$ \\
\hline \multirow[t]{2}{*}{ Ministério da Educação } & $-0.029^{* * *}$ & $0.058^{* * * x}$ \\
\hline & $(0.005)$ & $(0.010)$ \\
\hline \multirow[t]{2}{*}{ Ministério da Infraestrutura } & $0.141^{* *+*}$ & $0.347^{\text {tnt }}$ \\
\hline & $(0.008)$ & $(0.011)$ \\
\hline \multirow[t]{2}{*}{ Ministério da Justiça } & $0.045^{* * *}$ & $0.498^{* * *}$ \\
\hline & $(0.009)$ & $(0.010)$ \\
\hline \multirow[t]{2}{*}{ Ministério da Mulher, Família e Direitos Humanos } & $0.141^{* * *}$ & $-0.081^{+*+x}$ \\
\hline & $(0.011)$ & $(0.012)$ \\
\hline \multirow[t]{2}{*}{ Ministério da Saúde } & $-0.154^{* * *}$ & $-0.202^{+* * x}$ \\
\hline & $(0.005)$ & $(0.010)$ \\
\hline \multirow[t]{2}{*}{ Ministério da Transparência e Controladoria-Geral da União } & $-0.016^{* *}$ & $1.008^{*+*}$ \\
\hline & $(0.007)$ & $(0.012)$ \\
\hline \multirow[t]{2}{*}{ Ministério das Relações Exteriores } & $-0.146^{* * *}$ & $0.342^{*+*}$ \\
\hline & $(0.012)$ & $(0.023)$ \\
\hline \multirow[t]{2}{*}{ Ministério de Minas e Energia } & $0.067^{* \star * *}$ & $0.439^{*+*}$ \\
\hline & $(0.011)$ & $(0.014)$ \\
\hline
\end{tabular}




\begin{tabular}{|c|c|c|}
\hline & \multicolumn{2}{|c|}{ Log (Remuneração Bruta) } \\
\hline & (1) & (2) \\
\hline \multirow[t]{2}{*}{ Ministério do Meio Ambiente } & $-0.195^{*+*}$ & $0.258^{*+x}$ \\
\hline & $(0.009)$ & $(0.011)$ \\
\hline \multirow[t]{2}{*}{ Ministério do Turismo } & $0.067^{\star \star}$ & $-0.176^{\star \star *}$ \\
\hline & $(0.026)$ & $(0.033)$ \\
\hline \multirow[t]{2}{*}{ Anos na Carreira } & $0.014^{\star \star *}$ & $0.003^{* \star *}$ \\
\hline & $(0.000)$ & $(0.000)$ \\
\hline Controle de Função & Sim & Não \\
\hline Controle de UF & Sim & Sim \\
\hline Observações & 439,375 & 439,375 \\
\hline $\mathrm{R}^{2}$ Ajustado & 0.796 & 0.155 \\
\hline
\end{tabular}

Fonte: Elaborada pelo autor. 